\title{
Economics
}

The Open-Access, Open-Assessment E-Journal

Vol. 13, 2019-41 | October 10, 2019 | http://dx.doi.org/10.5018/economics-ejournal.ja.2019-41

\section{Shifting tax burden to top income earners: what is the best way to reduce inequality?}

\author{
Jorge Onrubia, Fidel Picos, and María del Carmen Rodado
}

\begin{abstract}
The authors analyze to what extent and how the tax burden should be shifted towards top income earners in order to reduce income inequality. Starting from Lambert and Aronson (Inequality decomposition analysis and the Gini coefficient revisited 1993) and Alvaredo (A note on the relationship between top income shares and the Gini coefficient 2011) decomposition by income groups, they prove that for three types of revenue-neutral linear personal income tax reforms (PIT) based on Pfähler (1984) the redistributive effect is always higher than before the reform; and when the size of the rich group is sufficiently small (e.g. 1\%), the best option is allocating tax changes proportionally to net income, and the worst doing it proportionally to tax liabilities. An empirical illustration of the theoretical results is provided using micro data from the Spanish PIT.
\end{abstract}

JEL D31 D33 D63 H23 H24

Keywords Top incomes; inequality; personal income tax; progressivity; redistribution

\section{Authors}

Jorge Onrubia, Complutense Institute for International Studies, ICEI (Complutense University of Madrid), FEDEA and GEN (Governance and Economics research Network). Faculty of Economics and Business, Department of Applied Economics (Public Economics and Political Economy), Madrid, Spain, jorge.onrubia@ccee.ucm.es

Fidel Picos, Fiscal Policy Analysis Unit, Joint Research Centre (JRC), European Commission, Sevilla, Spain

María del Carmen Rodado, Department of Applied Economics II, King Juan Carlos University, Madrid, Spain

Onrubia and Rodado acknowledge the financial support from the Spanish Ministry of Economy and Competitiveness (Project ECO2016-76506-C4-3-R). Earlier versions of this paper were presented at the 5th World Congress of the International Microsimulation Association (LISER, Esch-sur-Alzette, Luxembourg), the XXIII Spanish Meeting of Public Economics (Ourense, Spain), the XIX Spanish Meeting of Applied Economics (Sevilla, Spain), and seminars held at the University of Valencia and European Commission JRCSeville. They gratefully acknowledge the useful comments and suggestions received from referees and editor, Julio López-Laborda and the participants in the abovementioned meetings. All errors remain the responsibility of the authors. The views expressed are purely those of the authors and may not in any circumstances be regarded as stating an official position of the European Commission.

Citation Jorge Onrubia, Fidel Picos, and María del Carmen Rodado (2019). Shifting tax burden to top income earners: what is the best way to reduce inequality? Economics: The Open-Access, Open-Assessment E-Journal, 13 (2019-41): 1-17. http://dx.doi.org/10.5018/economics-ejournal.ja.2019-41 


\section{Introduction}

During the last decade, research in income inequality has paid special attention to top income earners. The publication of the thought-provoking book by Piketty (2014) has encouraged public debate by showing how in developed countries wealth has become concentrated in a very small proportion of citizens. As Atkinson et al. (2011) highlighted, the top percentile income share has more than doubled in the last decades (from less than 10 percent in the 1970s to over 20 percent in recent years). This trend is particularly noticeable in the United States, but it is also present in many other countries worldwide, including Southern European countries. The case of Spain is striking, since it shows one of the greatest rises in this concentration and also of income inequality in the European Union.

At the same time, top marginal tax rates on upper income earners have declined sharply in many OECD countries, particularly in Anglo-Saxon countries (Piketty et al., 2014), even though it is true that during the Great Recession a number of countries have approved tax hikes trying to halt the drop in public revenues (Förster et al., 2014). Discussions are still open on the relationship between the increase of the income share of the richest and the level at which they should be taxed 1 .

A recurrent idea in the public debate is the possibility of shifting part of the tax burden from lower and middle incomes to high incomes. Leaving aside the efficiency effects, one of the first relevant questions to analyse is the redistributive potential that the mentioned tax shift may have: even in a revenue-neutral reform, and accepting no behavioural responses, shifting part of the tax burden of the Personal Income Tax (PIT) towards the top income earners (e.g. the top $1 \%$ usually mentioned in these discussions) has obviously effects on the global progressivity of the tax, and consequently on its redistributive effect. Nevertheless, even though this effect is pursued with these reforms, it is necessary to assess their limits and their impact on the reduction of income inequality. It is obvious that arguments of confiscatory taxation and efficiency will limit the concentration of a relevant part of the tax burden on the top income earners. As far as we know, there is only some empirical evidence based in simulation exercises (Gale, Kearny and Orszag, 2015), but without a theoretical framework that incorporates the main underlying relations between tax progressivity, tax burden, and income distribution.

In relation to the previous argument a second question to analyse is the most convenient way of allocating individually the tax increase to the 'rich' and the corresponding tax decrease to the 'poor'. The way in which we implement the reform affects the structural progressivity of the tax and consequently its ability to reduce net income inequality, so it is necessary to analyse the implications of each possible alternative.

The aim of this paper is to analyse the two aforementioned questions. We offer a theoretical framework which extends the decomposition of the Reynolds and Smolensky (1977) redistribution index between progressivity and average tax rate proposed by Kakwani (1977), using the decomposition by income groups proposed by Lambert and Aronson (1993) and the

\footnotetext{
1 An example of this can be seen in the ongoing tax debate in the media and social networks launched by Alexandria Ocasio-Cortez, the newly-elected US congresswoman who calls for a $70 \%$ marginal tax rate on incomes over $\$ 10$ million. An interesting academic vision of this proposal can be seen in the recent opinion article published in The New York Times by Emmanuel Saez and Gabriel Zucman (Saez and Zucman, 2019).
} 
relationship between top income shares and the Gini coefficient established by Alvaredo (2011). In order to analyse the alternatives for reforming the PIT with the aim of increasing its redistributive effect through a higher level of progressivity on the top income earners, we consider the linear tax reform alternatives studied in Pfähler (1984), both for implementing tax cuts and tax increases. The neutral local progressivity properties of this kind of PIT reforms à la Pfähler (1984) allow us to obtain several relevant results about top income taxation.

As an illustration of the theoretical results we evaluate the different reform types using microdata from the 2011 Spanish PIT Return Sample disseminated by the Spanish Institute for Fiscal Studies (Instituto de Estudios Fiscales, IEF) and the Spanish Tax Agency (Agencia Estatal de Administración Tributaria, AEAT). In order to carry out this exercise we use a stylized transformation of the Spanish PIT so that tax liabilities depend only on gross income, without taking into account any non-income attribute, but keeping the revenue and redistributive effect of the actual tax unchanged.

The rest of the paper is organized as follows. In the second section, we introduce the theoretical framework used to decompose global progressivity and redistributive effect by income groups. The third section presents the linear reforms of progressive PITs considered in our analysis, and the theoretical results of the paper. The fourth section offers some considerations on the real-world implementation of the tax reforms analysed. In the fifth section, we show an empirical illustration using Spanish PIT microdata, including a brief presentation of the data and the results of the microsimulation exercises carried out. The sixth section concludes.

\section{Theoretical framework}

\subsection{Decomposing global PIT progressivity and redistributive effect by income level groups}

In order to decompose the redistributive effect among different groups we can take as a starting point the expression proposed by Lambert and Aronson (1993) to split the Gini index ( $G$ ) for $h$ groups of population:

$$
G_{Y}=G_{Y}^{B}+\sum_{h} p_{h} S_{Y_{h}} G_{Y_{h}}+R
$$

where $G_{Y}^{B}$ is a between-groups component, that expresses the inequality among the $h$ groups assuming that all individuals within each group hold the same income $\mu_{Y_{h}}$, and $\sum_{h} p_{h} S_{Y_{h}} G_{Y_{h}}$ is the within-groups component that is calculated as the sum of the inequality indices within each group weighted by their share in the total population $\left(p_{h}=N_{h} / N\right)$ and total income $\left(s_{Y_{h}}=\right.$ $Y_{h} / Y$ ). Finally $R$ represents an extra term to make the decomposition work when the subgroup income ranges overlap, to the extent that, as a general rule, the Gini coefficient fails to decompose additively into between and within-group components. ${ }^{2}$

\footnotetext{
2 See Lambert (2001:114) for some interpretations of R term.
} 
As a specific case of (1), Alvaredo (2011) proposes an expression for the Gini index that takes into account the existence of two groups only differentiated by their income level (group '99', composed of the first 99 centiles of individuals, and group '100' for the remaining top $1 \%)$ :

$$
G_{Y}=\left(s_{Y}-p\right)+(1-p)\left(1-s_{Y}\right) G_{Y}^{99}+p s_{Y} G_{Y}^{100}
$$

where $p$ represents the population share of group 100 (i.e. 0.01 ) and $s_{Y}$ is the share of gross income held by that group. Complementarily, $1-p$ is the population share of group 99 (0.99) and $1-s_{Y}$ the gross income share of that group. $G_{Y}^{99}$ and $G_{Y}^{100}$ are the Gini indices of gross income within each group. Now, $s_{Y}-p$ is the 'between' component, while the rest of expression (2) contains the two 'within' components. In this partition there is no overlapping effect.

Let $G_{Y-T}$ the net (after the tax T) income inequality. Rearranging terms we can write the Reynolds-Smolensky (1977) redistribution index $\left(\Pi^{R S}\right)$ as follows:

$$
\begin{aligned}
& \Pi^{R S}=G_{Y}-G_{Y-T}=\left(s_{Y}-s_{Y-T}\right)+(1-p)\left(1-s_{Y}\right) \Pi_{R S}^{99}+p s_{Y} \Pi_{R S}^{100}- \\
& \left(s_{Y}-s_{Y-T}\right)\left[(1-p) G_{Y-T}^{99}+p G_{Y-T}^{100}\right]
\end{aligned}
$$

where $s_{Y-T}$ is the proportion of net income accumulated by group 100 and $\Pi_{R S}^{99}$ and $\Pi_{R S}^{100}$ are the Reynold-Smolensky indices for groups 99 and 100 respectively. We assume that the tax applied has a structure $T=t(y)$ where tax liability $T$ only depends (positively) on income, and that its application does not produce re-ranking. Overall redistribution in (3) can be then understood as the sum of a 'between effect' $\left(s_{Y}-s_{Y-T}\right)$, two weighted 'within effects' $\left((1-p)\left(1-s_{Y}\right) \Pi_{R S}^{99}\right.$ and $\left.s_{Y} \Pi_{R S}^{100}\right)$ and an 'interaction term' $\left(-\left(s_{Y}-s_{Y-T}\right)\left[(1-p) G_{Y-T}^{99}+p G_{Y-T}^{100}\right]\right)$.

We can further develop (3) to embed the interaction term into the within terms, as follows:

$\Pi^{R S}=\left(s_{Y}-s_{Y-T}\right)+(1-p)\left[\left(1-s_{Y}\right) G_{Y}^{99}-\left(1-s_{Y-T}\right) G_{Y-T}^{99}\right]+p\left[s_{Y} G_{Y}^{100}-s_{Y-T} G_{Y-T}^{100}\right]$

where now the new within effects are expressed in terms of pseudo-Reynolds-Smolensky indices.

Additionally, applying the Kakwani (1977) decomposition we can explain Equation (4) combining revenue and progressivity effects (the latter measured by the Kakwani progressivity index, $\Pi^{K}$ ), as follows ${ }^{3}$ :

$\Pi^{R S}=\frac{t}{1-t}\left\{\left(s_{T}-s_{Y}\right)+(1-p)\left[\left(1-s_{T}\right) G_{T}^{99}-\left(1-s_{Y}\right) G_{Y}^{99}\right]+p\left(G_{T}^{100} s_{T}-G_{Y}^{100} s_{Y}\right)\right\}$

where $t$ is the global average tax rate, $G_{T}^{99}$ and $G_{T}^{100}$ are the Gini indices of tax liabilities, and the within effects are now expressed in terms of pseudo-Kakwani progressivity indices.

\footnotetext{
3 The Kakwani progressivity index is defined as $\Pi^{K}=G_{T}-G_{Y}$. Since $T$ is only a function of $y$, there is no re-ranking effect in terms of net (after-tax) income, therefore the Gini and concentration index of tax liabilities coincide.
} 


\section{2}

\section{Linear reforms of progressive PITs}

A reform of a progressive personal income tax $T^{(1)}(y)$ that implies an increase or a reduction of the tax burden $( \pm \lambda)$ for all taxpayers can be treated as a linear transformation of the original tax. The new $\operatorname{tax} T^{(2)}(y)$ will raise a total revenue of $T^{(2)}=(1 \pm \lambda) T^{(1)}$. Following Pfähler (1984) there are three types of relevant linear tax reforms $(j=\{a, b, c\})$ neutral in relation to different local progressivity measures. ${ }^{4}$

(i) The reduction (increase) of each taxpayer's tax liability is a constant fraction $\alpha$ of the original tax liability, $T_{a}^{(2)}(y)=(1 \pm \alpha) T^{(1)}(y)$, where $\alpha=\lambda$, and the liability progression is kept constant.

(ii) The reduction (increase) of each taxpayer's tax liability is a constant fraction $\beta$ of the original net income, $T_{b}^{(2)}(y)=T^{(1)}(y) \pm \beta\left[y-T^{(1)}(y)\right]$, where $\beta=\lambda T^{(1)} /\left[Y-T^{(1)}\right]$, and the residual progression is kept constant.

(iii) The reduction (increase) of each taxpayer's tax liability is a constant fraction $\varsigma$ of gross income, $T_{c}^{(2)}(y)=T^{(1)}(y) \pm \varsigma y$, where $\varsigma=\lambda T^{(1)} / Y$, and the average rate progression is kept constant.

For the same revenue change it results that $\varsigma=\alpha \bar{t}=\beta(1-\bar{t})$, where $\bar{t}$ is the average effective rate of the original tax, $\bar{t}=T^{(1)} / Y$.

According to Pfähler (1984) and the well-known identity in terms of Lorenz curves $L_{Y} \equiv$ $(1-\bar{t}) L_{Y-T(Y)}+\bar{t} L_{T}$, we can sort reforms $a, b$ and $c$ according to their global redistribution and progressivity. Formally, in redistributive terms, the following order is obtained (from lower to higher inequality):

$$
L_{Y-T(Y)}^{1}=L_{Y-T(Y)}^{2 b}>L_{Y-T(Y)}^{2 c}>L_{Y-T(Y)}^{2 a}>L_{Y}
$$

For tax increases (denoted with ') the ranking is the opposite:

$$
L_{Y-T(Y)}^{2 a \prime}>L_{Y-T(Y)}^{2 c \prime}>L_{Y-T(Y)}^{2 b \prime}=L_{Y-T(Y)}^{1}>L_{Y}
$$

In terms of progressivity the order for tax reductions will be (from lower to higher):

$$
L_{Y}>L_{T(Y)}^{1}=L_{T(Y)}^{2 a}>L_{T(Y)}^{2 c}>L_{T(Y)}^{2 b}
$$

For tax increases the ranking is again the opposite:

$$
L_{Y}>L_{T(Y)}^{2 b \prime}>L_{T(Y)}^{2 c \prime}>L_{T(Y)}^{2 a \prime}=L_{T(Y)}^{1}
$$

\footnotetext{
4 See Musgrave and Thin (1948) for definitions of these measures of progression.
} 


\section{Shifting tax burden to top income earners through yield- equivalent linear PIT reforms}

Keeping in mind the class of reforms explained above, we can define a generic revenue-neutral reform of the PIT so that the revenue obtained from the $99 \%$ poorest taxpayers is reduced in a fraction $\lambda$ which is now shifted to the $1 \%$ richest taxpayers, i.e. $T^{(2)}=(1-\lambda) T^{99(1)}+$ $T^{100(1)}+\lambda T^{99(1)}$. Alternatively, the revenue shifted can be expressed as a fraction $\ell$ of total revenue $\left(\ell T^{(1)}\right)$ so that, $T^{(2)}=\left(1-s_{T}-\ell\right) T^{(1)}+\left(s_{T}+\ell\right) T^{(1)}$.

Now the relevant question is how this shift of $\ell$ from the 'poor' to the 'rich' changes the total redistributive effect of the PIT. This can be done in an infinite number of ways, but we can limit the reform to the three types of linear changes explained before, which can be implemented in nine different ways (the combination of $a, b$ and $c$ in the tax reduction of group ' 99 ' and in the increase of group '100'). To evaluate these reforms in redistributive terms we apply the results of Equations (6) and (7) to Equation (3), and we see that:

(i) The between effect $s_{Y}-s_{Y-T}$ is positive in the nine reforms, because the tax increase for group 100 makes its net income share $\left(s_{Y-T}\right)$ smaller and therefore $s_{Y}-s_{Y-T}$ larger.

(ii) Following Equation (6) the within effect of group $99\left((1-p)\left(1-s_{Y}\right) \Pi_{R S}^{99}\right)$ will be unchanged (reform $b$ ) or will decrease (reforms $a$ and $c$ ).

(iii) Following Equation (7) the within effect of group $100\left(p s_{Y} \Pi_{R S}^{100}\right)$ will be unchanged (reform $b$ ) or will increase (reforms $a$ and $c$ ).

(iv) The change in the interaction term $\left(-\left(s_{Y}-s_{Y-T}\right)\left[(1-p) G_{Y-T}^{99}+p G_{Y-T}^{100}\right]\right)$ is always negative since all their factors are positive and its product is preceded by a minus sign.

(v) This implies an a priori ambiguous result in the nine possible combinations. However it is possible to obtain unambiguous conclusions for the three cases in which we apply the same type of reforms to both groups, namely, reforms $a a^{\prime}, b b^{\prime}$ and $c c^{\prime}$.

Proposition 1. Let $\mathrm{aa}^{\prime}, \mathrm{bb}^{\prime}$ and $\mathrm{cc}^{\prime}$ be three alternative yield-equivalent reforms of the progressive tax $\mathrm{T}=\mathrm{t}(\mathrm{y})$ that reduce all tax liabilities in group 99 proportionally to, respectively, their original tax liabilities (a), original net income (b), and original gross income (c), and increase all tax liabilities in group 100 proportionally to, respectively, their original tax liability (a'), original net income (b'), and original gross income (c), all of them will increase the global redistributive effect.

Proof (for $\boldsymbol{a} \boldsymbol{a}^{\prime}$ ). According to Equations (8) and (9) we know that the Gini indices of the initial tax liabilities for both groups are not affected by the reform. Expressing Equation (5) in terms of the fraction $\ell$ of total revenue we can write the global redistributive effect of the new $\operatorname{tax}\left(\Pi^{R S\left(2 a a^{\prime}\right)}\right)$ as:

$$
\begin{aligned}
& \Pi^{R S\left(2 a a^{\prime}\right)}=\frac{t}{1-t}\left\{\left(s_{T}+\ell-s_{Y}\right)+(1-p)\left[G_{T}^{99(1)}\left(1-s_{T}-\ell\right)-G_{Y}^{99}\left(1-s_{Y}\right)\right]+\right. \\
& \left.p\left(G_{T}^{100(1)}\left(s_{T}+\ell\right)-G_{Y}^{100} s_{Y}\right)\right\}
\end{aligned}
$$

Isolating $\Pi^{R S(1)}$ in (10) we obtain: 
$\Pi^{R S\left(2 a a^{\prime}\right)}=\Pi^{R S(1)}+\frac{t}{1-t} \ell\left\{1-(1-p) G_{T}^{99(1)}+p G_{T}^{100(1)}\right\}$

It is straightforward to show that $\Pi^{R S(2 a a)}>\Pi^{R S(1)}$, since $\frac{t}{1-t} \ell>0,1-(1-p) G_{T}^{99(1)}>$ 0 and $+p G_{T}^{100(1)}>0$.

Proof (for $\boldsymbol{b}^{\prime}$ ). According to Equations (6) and (7) we know that the initial Gini indices of net income for both groups are not affected by the reform. We also know that the new liability share of group 100 is $s_{T}+\ell$, so we can express their new net income share as $s_{Y-T}-\ell \frac{t}{1-t}$. Therefore using Equation (4) we can write the global redistributive effect of the new tax $\left(\Pi^{R S(2 b b)}\right)$ as:

$$
\begin{aligned}
& \Pi^{R S\left(2 b b^{\prime}\right)}=\left(s_{Y}-s_{Y-T}+\ell \frac{t}{1-t}\right)+(1-p)\left[\left(1-s_{Y}\right) G_{Y}^{99}-\left(1-s_{Y-T}+\ell \frac{t}{1-t}\right) G_{Y-T}^{99(1)}\right]+ \\
& p\left[s_{Y} G_{Y}^{100}-\left(s_{Y-T}-\ell \frac{t}{1-t}\right) G_{Y-T}^{100(1)}\right]
\end{aligned}
$$

Isolating $\Pi^{R S(1)}$ in (12) we obtain:

$$
\Pi^{R S\left(2 b b^{\prime}\right)}=\Pi^{R S(1)}+\frac{t}{1-t} \ell\left\{1-(1-p) G_{Y-T}^{99(1)}+p G_{Y-T}^{100(1)}\right\}
$$

Since $\frac{t}{1-t} \ell>0,1-(1-p) G_{Y-T}^{99(1)}>0$ and $+p G_{Y-T}^{100(1)}>0$, the condition $\Pi^{R S\left(2 b b^{\prime}\right)}>$ $\Pi^{R S(1)}$ is fulfilled.

Proof (for $\boldsymbol{c} \boldsymbol{c}^{\prime}$ ). Following Rietveld (1990) we can express the Gini index of the new tax liability as the weighted sum of the Gini index of the original tax liability $\left(G_{T}^{100(1)}\right)$ plus the Gini index of the tax increase, which equals the Gini index of gross income $\left(G_{Y}\right)$ :

$$
G_{T}^{100\left(2 c^{\prime}\right)}=\frac{s_{T}}{s_{T}+\ell} G_{T}^{100(1)}+\frac{\ell}{s_{T}+\ell} G_{Y}
$$

Applying the same rule to group 99 we have:

$$
G_{T}^{99\left(2 c^{\prime}\right)}=\frac{\left(1-s_{T}\right)}{\left(1-s_{T}-\ell\right)} G_{T}^{99(1)}-\frac{\ell}{\left(1-s_{T}-\ell\right)} G_{Y}
$$

Replacing Equations (14) and (15) in Equation (5) we get:

$$
\begin{aligned}
& \Pi^{R S}=\frac{t}{1-t}\left\{\left(s_{T}+\ell-s_{Y}\right)+(1-p)\left[\left(\left(1-s_{T}\right) G_{T}^{99(1)}-\ell G_{Y}\right)-G_{Y}^{99}\left(1-s_{Y}\right)\right]+\right. \\
& \left.p\left(\left(s_{T} G_{T}^{100(1)}+\ell G_{Y}\right)-G_{Y}^{100} s_{Y}\right)\right\}
\end{aligned}
$$

Isolating $\Pi^{R S(1)}$ in (16) we obtain:

$$
\Pi^{R S\left(2 c c^{\prime}\right)}=\Pi^{R S(1)}+\frac{t}{1-t} \ell\left\{1-(1-p) G_{Y}^{99}+p G_{Y}^{100}\right\}
$$

Once more, it is straightforward to show that $\Pi^{R S\left(2 c c^{\prime}\right)}>\Pi^{R S(1)}$, since $\frac{t}{1-t} \ell>0$, $1-(1-p) G_{Y}>0$ and $+p G_{Y}>0$. 
Proposition 2. Let $\mathrm{aa}^{\prime}, \mathrm{bb}^{\prime}$ and $\mathrm{cc}^{\prime}$ be three yield-equivalent reforms that reduce all tax liabilities in group 99 and increase all tax liabilities in group 100 at the same rate $\ell$, and share this rate proportionally to, respectively, their original tax liability, original net income and gross income, their ranking in terms of redistribution is ambiguous.

Proof. Consider that gross income in group 99 is distributed equally among all individuals. In this case $G_{Y}^{99}=G_{T}^{99}=G_{Y-T}^{99}=0$, so Equations (11), (13) and (17) will be:

$$
\begin{aligned}
& \Pi^{\mathrm{RS}\left(2 \mathrm{aa}^{\prime}\right)}=\Pi^{\mathrm{RS}(1)}+\frac{\mathrm{t}}{1-\mathrm{t}} \ell\left\{1+\mathrm{pG}_{\mathrm{T}}^{100}\right\} \\
& \Pi^{\mathrm{RS}\left(2 \mathrm{bb}^{\prime}\right)}=\Pi^{\mathrm{RS}(1)}+\frac{\mathrm{t}}{1-\mathrm{t}} \ell\left\{1+\mathrm{pG}_{\mathrm{Y}-\mathrm{T}}^{100}\right\} \\
& \Pi^{\mathrm{RS}\left(2 \mathrm{cc}^{\prime}\right)}=\Pi^{\mathrm{RS}(1)}+\frac{\mathrm{t}}{1-\mathrm{t}} \ell\left\{1+\mathrm{pG}_{\mathrm{Y}}^{100}\right\}
\end{aligned}
$$

Since $G_{T}^{100}>G_{Y}^{100}>G_{Y-T}^{100}$, then $\Pi^{R S\left(2 a a^{\prime}\right)}>\Pi^{R S\left(2 c c^{\prime}\right)}>\Pi^{R S\left(2 b b^{\prime}\right)}$.

Consider now that gross income in group 100 is distributed equally among all individuals. In this case $G_{Y}^{100}=G_{T}^{100}=G_{Y-T}^{100}=0$, so Equations (11), (13) and (17) will be:

$$
\begin{aligned}
& \Pi^{\mathrm{RS}\left(2 \mathrm{aa}^{\prime}\right)}=\Pi^{\mathrm{RS}(1)}+\frac{\mathrm{t}}{1-\mathrm{t}} \ell\left\{1-(1-\mathrm{p}) \mathrm{G}_{\mathrm{T}}^{99}\right\} \\
& \Pi^{\mathrm{RS}\left(2 \mathrm{bb}^{\prime}\right)}=\Pi^{\mathrm{RS}(1)}+\frac{\mathrm{t}}{1-\mathrm{t}} \ell\left(1-(1-\mathrm{p}) \mathrm{G}_{\mathrm{Y}-\mathrm{T}}^{99}\right) \\
& \Pi^{\mathrm{RS}\left(2 \mathrm{cc}^{\prime}\right)}=\Pi^{\mathrm{RS}(1)}+\frac{\mathrm{t}}{1-\mathrm{t}} \ell\left\{1-(1-\mathrm{p}) \mathrm{G}_{\mathrm{Y}}^{99}\right\}
\end{aligned}
$$

Since $G_{T}^{99}>G_{Y}^{99}>G_{Y-T}^{99}$, then $\Pi^{R S\left(2 a a^{\prime}\right)}<\Pi^{R S\left(2 c c^{\prime}\right)}<\Pi^{R S\left(2 b b^{\prime}\right)}$.

Given that these two cases give opposite results, the ranking of the three reforms in redistribution terms is generally ambiguous. Therefore, the relative order among the three tax reform alternatives remains an empirical issue.

Proposition 3. For asymmetric partitions of the population where $\mathrm{p} \rightarrow 0$ the following order is fulfilled: $\Pi^{\mathrm{RS}\left(2 \mathrm{bb}^{\prime}\right)}>\Pi^{\mathrm{RS}\left(2 \mathrm{cc}^{\prime}\right)}>\Pi^{\mathrm{RS}\left(2 \mathrm{aa} a^{\prime}\right)}$.

Proof. Applying $p \rightarrow 0$ to Equations (11), (13) and (17) we obtain:

$$
\begin{aligned}
& \lim _{p \rightarrow 0} \Pi^{R S\left(2 a a^{\prime}\right)}=\Pi^{R S(1)}+\frac{t}{1-t} \ell\left(1-G_{T}^{99(1)}\right) \\
& \lim _{\mathrm{p} \rightarrow 0} \Pi^{\mathrm{RS}(2 \mathrm{bb} \prime)}=\Pi^{\mathrm{RS}(1)}+\frac{\mathrm{t}}{1-\mathrm{t}} \ell\left(1-\mathrm{G}_{\mathrm{Y}-\mathrm{T}}^{99(1)}\right) \\
& \lim _{\mathrm{p} \rightarrow 0} \Pi^{\mathrm{RS}(2 \mathrm{cc} \prime)}=\Pi^{\mathrm{RS}(1)}+\frac{\mathrm{t}}{1-\mathrm{t}} \ell\left(1-\mathrm{G}_{\mathrm{Y}}^{99(1)}\right)
\end{aligned}
$$

Since $G_{T}^{99}>G_{Y}^{99}>G_{Y-T}^{99}$, then $\Pi^{R S\left(2 b b^{\prime}\right)}>\Pi^{R S\left(2 c c^{\prime}\right)}>\Pi^{R S\left(2 a a^{\prime}\right)}$. 


\section{$4 \quad$ Implementing linear tax reforms in the real world}

As presented in Section 2.2, the three types of linear tax reforms $(j=\{a, b, c\})$ proposed by Pfähler (1984) are originally defined in terms of tax liabilities, $T_{j}^{(2)}(y)$, or in other words, in terms of average tax rates (dividing tax liabilities by the respective incomes). Since actual taxes are usually defined in terms of marginal tax rates, the application of these results to a real-world tax system requires additional conditions.

First, any of the tax reform alternatives considered should not cause re-ranking, in terms of net income, between an individual of the group affected by the tax hike and an individual of the group benefited from the tax cut. This may happen in the theoretical framework used here: if we choose two individuals sufficiently close to the income limit $\left(y^{*}\right)$ that divides the two groups, one above and one below, the net income of the richer may fall below the net income of the poorer, therefore producing re-ranking.

For the non-re-ranking condition to be fulfilled, it is enough that the tax reforms can be redefined in marginal terms. This allows maintaining the results obtained in Pfähler (1984) and, consequently, those achieved in this paper. If the linear reforms (i), (ii) and (iii), expressed in terms of tax liability, are derived with respect to income, we obtain, (i') $t^{\prime}{ }_{a}^{(2)}(y)=$ $(1 \pm \alpha) t^{\prime(1)}, \forall y>0$; (ii') $t_{b}^{\prime(2)}(y)=t^{\prime(1)} \pm \beta\left[1-t^{\prime(1)}\right], \forall y>0$; (iii') $t^{\prime}{ }_{c}^{(2)}(y)=$ $t^{\prime(1)} \pm \varsigma, \forall y>0$, where $t^{\prime(1)}$ and $t^{\prime}{ }_{j}^{(2)}$ are the marginal tax rates before and after the reform, respectively. It can be seen that the characterizing parameters $(\alpha, \beta, \varsigma)$ remain unchanged when a marginal approach is adopted. By applying definitions (i'), (ii') and (iii') to the marginal tax rates corresponding to the different brackets of the pre-reform tax schedule, we can calculate the new marginal tax rates post-reform.

Nevertheless, in order to guarantee that the required non-re-ranking condition between groups is met, it is necessary that after the reform a single tax schedule is applied. This can be achieved by treating differently the marginal rates below and above threshold $y^{*}$. On one hand, all pre-reform marginal rates up to $y^{*}$ must be reduced according to the option chosen. On the other hand, all pre-reform marginal rates applicable to income above that limit must be increased according to the same option. It is clear, however, that a multi-bracket tax schedule like this forces to readjust the value of the linear parameters to ensure the target level of revenue collection.

\section{$5 \quad$ An empirical illustration using Spanish PIT microdata}

To illustrate the results of the previous sections we use 2011 Spanish PIT microdata to simulate the three linear tax reforms considered in the theoretical analysis: $a a^{\prime}$ (changes proportional to tax liability), $b b^{\prime}$ (changes proportional to net income) and $c c^{\prime}$ (changes proportional to gross income). In particular we use the 2011 Spanish PIT Return Sample disseminated by the Spanish Institute for Fiscal Studies (Instituto de Estudios Fiscales, IEF) and the Spanish Tax Agency (Agencia Estatal de Administración Tributaria, AEAT) which contains more than 2 million 
observations representative of more than 19 million tax returns. ${ }^{5}$ Table 1 shows the descriptive statistics of the microdata regarding gross income.

In order to assess the reforms we cannot use the 2011 Spanish PIT as a reference, since like any other real income tax it does not fit the $T=t(y)$ model, because tax liabilities depend not only on income but also on other variables (income type, age, personal and family characteristics, region, tax incentives, etc.). In order to stay as close as possible to the real tax we simulate a stylized tax $T=t(y)$ with the same revenue and redistribution impact as the tax actually applied in 2011. To ensure that average rates are also distributed in a similar way we keep the basic structure of the real tax, i.e. $T=t(y)=f(y-d(y))-c(y)$, where $f(\cdot)$ represents the tax schedule, $d(y)$ are tax deductions and $c(y)$ tax credits. All these parameters depend only on total income or are constant. In particular, in our microsimulation exercise $f(\cdot)$ is the real tax schedule applied in 2011 to 'general income' (Spanish PIT also incorporates a different schedule for 'savings income'), while $d(y)$ has a fixed part and a part that is proportional to income (but with a fixed limit), and $c(y)$ is constant (but limited to ensure that $T \geq 0$ ). All these values try to reproduce the real variability originated by tax treatments based on non-income attributes. Table 2 shows the final parameters chosen.

Taking this stylized tax as a starting point we simulate the three types of reform $\left(a a^{\prime}\right.$, $b b^{\prime}$ and $c c^{\prime}$ ) for several values of $\ell$. We start by $\ell=0.01$ (i.e. we shift $1 \%$ of the overall revenue from group 99 to group 100) and keep increasing this value (in steps of 0.01 ) while the effective average tax rate of group 100 is lower than 0.50 (this happens when $\ell=0.09$, where the effective tax rate is 0.4913). Although these simulations are only an illustration of the previous theoretical developments, we understand that this may be a reasonable limit for the average tax rate of that group. Table A.1 in the Appendix shows all the shares, rates and Gini and concentration indices calculated in the simulations. Figure 1 summarizes graphically the overall progressivity and redistributive effect of all the reforms simulated.

This figure confirms empirically the results of Proposition 1: all the reforms are more redistributive than the original tax. Furthermore, it shows that the ranking from more to less

Table 1. Descriptive statistics of the 2011 Spanish PIT microdata

\begin{tabular}{|c|c|c|c|c|}
\hline \multicolumn{2}{|c|}{ Concept } & Group 99 & Group 100 & Total \\
\hline \multicolumn{2}{|c|}{ Number of observations } & $1,885,082$ & 146,495 & $2,031,577$ \\
\hline \multicolumn{2}{|c|}{ Population represented } & $19,235,740$ & 194,300 & $19,430,040$ \\
\hline \multirow{6}{*}{$\begin{array}{l}\text { Gross } \\
\text { income }\end{array}$} & Total $(€)$ & $409,096,697,360$ & $39,226,087,286$ & $448,322,784,646$ \\
\hline & Average $(€)$ & 21,268 & 201,885 & 23,074 \\
\hline & Standard dv. $(€)$ & 15,461 & 557,243 & 60,537 \\
\hline & Minimum (€) & 0 & 102,063 & 0 \\
\hline & Maximum (€) & 102,063 & $96,182,743$ & $96,182,743$ \\
\hline & Gini index & 0.37659546 & 0.35587053 & 0.41801533 \\
\hline
\end{tabular}

Source: Own elaboration from 2011 Spanish PIT Return Sample provided by AEAT and IEF.

\footnotetext{
5 This specific sample is officially named Muestra IRPF 20011 IEF-AEAT (Declarantes). Detailed information on the database can be found in Pérez et al. (2014).
} 
Table 2: Design parameters of the stylized tax equivalent to the 2011 Spanish PIT

\begin{tabular}{|c|c|c|c|}
\hline Parameter & & & Comments \\
\hline \multirow{7}{*}{$f(\cdot)$} & \multicolumn{2}{|c|}{ Taxable Income (EUR) - Marginal Rate } & \multirow{7}{*}{$\begin{array}{l}\text { Progressive tax schedule applied to } \\
\text { 'general income' in } 2011\end{array}$} \\
\hline & $0-17707.20$ & $24 \%$ & \\
\hline & $17707.20-33007.20$ & $28 \%$ & \\
\hline & 33007.20 - 53407.20 & $37 \%$ & \\
\hline & $53407.20-120000.20$ & $43 \%$ & \\
\hline & $120000.20-175000.20$ & $44 \%$ & \\
\hline & $>175000.20$ & $45 \%$ & \\
\hline$d(\cdot)$ & \multicolumn{2}{|c|}{$\min (2500+\min (.1372186 y, 50000), y)$} & $\begin{array}{l}\text { EUR 2,500, plus } 13.72186 \% \text { of gross } \\
\text { income with a limit of EUR } 50,000 \text {. } \\
\text { The deduction cannot be higher than } \\
\text { gross income. }\end{array}$ \\
\hline$c(\cdot)$ & \multicolumn{2}{|c|}{$\min (1591, f(y-d(y)))$} & $\begin{array}{l}\text { EUR } 1,591 \text { with the limit of the gross } \\
\text { tax liability previously calculated }\end{array}$ \\
\hline
\end{tabular}

Source: Own elaboration.

Figure 1: Progressivity and redistribution of the PIT reforms

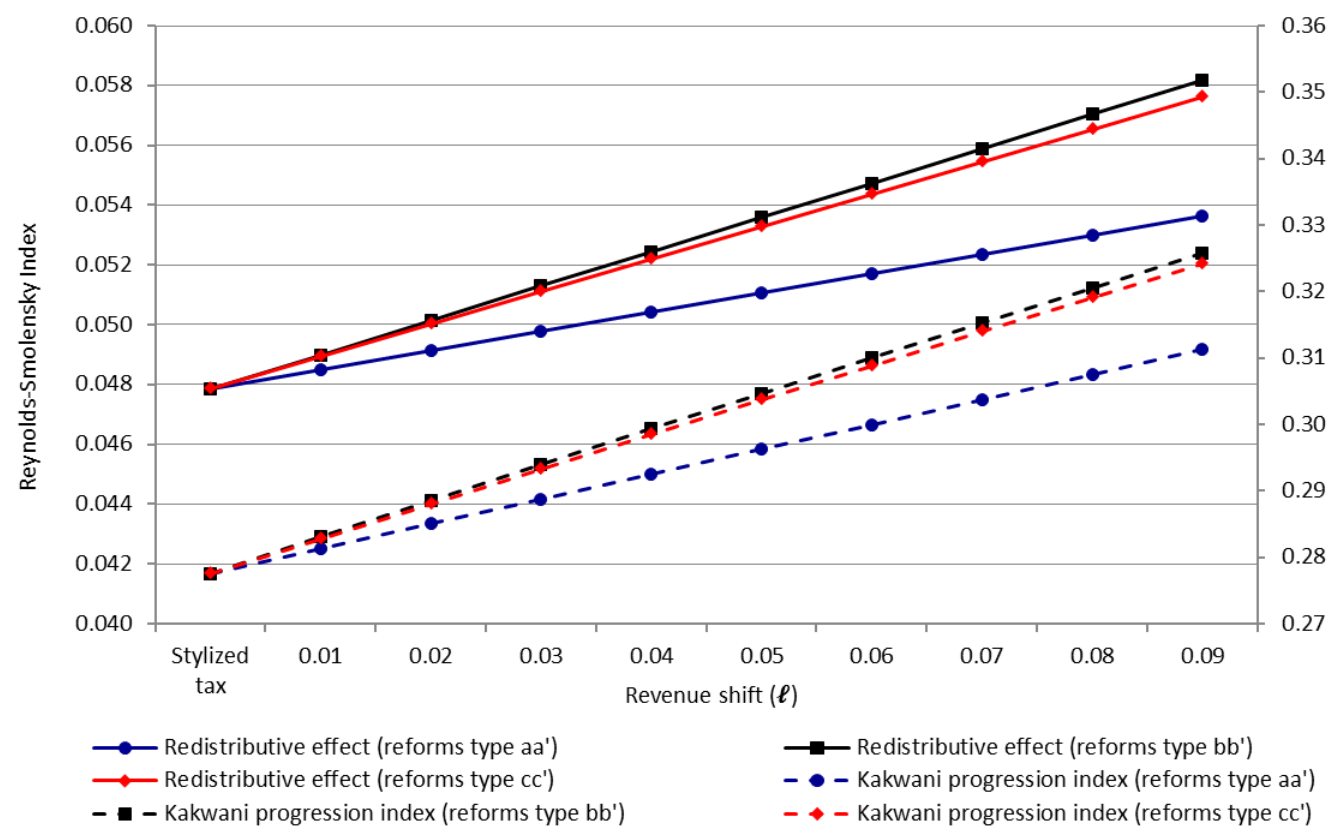

Source: Own elaboration using the 2011 Spanish PIT Return Sample provided by AEAT and IEF. 
redistributive is $b b^{\prime}, c c^{\prime}, a a^{\prime}$, what is consistent with Proposition 3 (which is obtained under the assumption $\lim p \rightarrow 0$ ). In our illustration, this result is fulfilled for $p=0.01$. Nevertheless, determining the value of $p$ is an empirical issue, not implying that the result has to be very close to zero.

However, it can be seen that the distance between $a a^{\prime}$ and $c c^{\prime}$ is much higher than between $c c^{\prime}$ and $b b^{\prime}$, which is related to the higher distance between $G_{T}$ and $G_{Y}$ than between $G_{Y}$ and $G_{Y-T}$, as can be easily deduced from Kakwani (1977). We also see that within each reform type the redistributive effect rises as $\ell$ increases, which is a direct consequence of Equations (11), (13) and (17).

Figure 2 shows the decomposition of the redistributive effect using Equation (3). We see that in all the reforms the 'between' effect increases while the 'interaction' effect decreases. Both the 'within 99' and 'within 100' effects are constant for $b b^{\prime}$, which can be derived directly from Equation (3); for $a a^{\prime}$ and $c c^{\prime}$ the 'within 99 effect' decreases and the 'within 100 effect' increases, but the latter effect is almost negligible due to the small population share of the last centile. In general, the total redistributive effect is driven mostly by the 'within 99 effect', although the 'between effect' exceeds it for high values of $\ell$. Finally, the 'interaction' effect grows in the opposite direction as $\ell$ increases, so it smooths the increase of total redistribution.

Figure 2: Decomposition of the redistributive effect

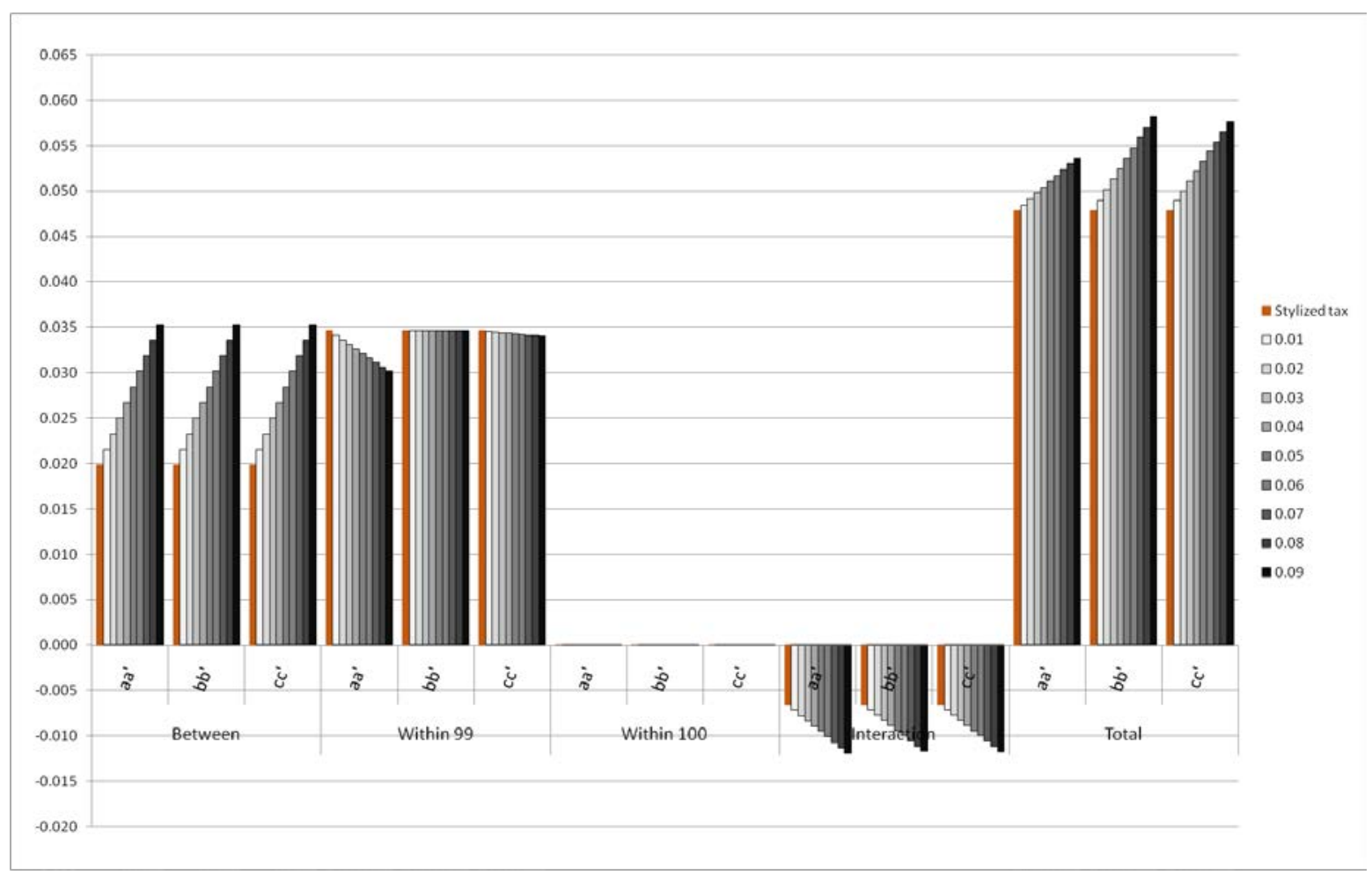

Source: Own elaboration from 2011 Spanish PIT Return Sample provided by AEAT and IEF. 


\section{$5 \quad$ Concluding remarks}

Throughout this paper we have developed a methodology to assess PIT reforms that shift part of the tax burden towards the top $1 \%$ income earners, keeping overall revenue constant. Based on the Kakwani (1977) decomposition of the Reynolds-Smolensky index, and using the decompositions by income groups by Lambert and Aronson (1993) and Alvaredo (2011), we have developed a theoretical framework that allow us to obtain conclusions in terms of redistribution on a set of linear tax reforms based on Pfähler (1984). We also illustrate the results with an empirical exercise using a Spanish PIT microdata sample. The main conclusions of this paper are the following:

(i) The overall redistribution of this type of tax reforms can be decomposed in a 'between' effect (that measures the pure effect of the shift) and a 'within' effect for each group (that measures how the distribution of tax changes within the group affects total redistribution). Depending on the way we make the decomposition there may be an additional interaction term'.

(ii) In principle, the redistributive result of this linear tax reforms is ambiguous in redistributive terms, since there are positive effects (between and within for the 'rich') and negative effects (within for the 'poor' and interaction).

(iii) For three types of reforms based on Pfähler (1984) (which consist of allocating the tax changes proportionally to tax liabilities, net income or gross income) we show that the redistributive effect is always higher than before the reform.

(iv) The ranking among those three types of reform is ambiguous except when the population size of the rich group is sufficiently small (empirically verified for Spain when $\mathrm{p}=$ $1 \%)$. In this case the best option is allocating tax changes proportionally to net income, and the worst doing it proportionally to tax liabilities.

As explained in the introduction, the motivation of this paper was to shed light on the potential capacity to reduce income inequality through a tax increase on the highest income individuals. The main objective of our study has been to develop a theoretical framework for accurately analysing the underlying drivers of the redistributive effects of this kind of reforms. Nevertheless, there is still space for further research. In particular, as a second step we consider it crucial to extend our theoretical framework to incorporate behavioural responses to the tax changes proposed.

Finally, it cannot be ignored that the political economy of tax reforms has important implications for explaining the changes adopted in real-world tax systems (Diamond and Saez, 2011; Hettich et al., 2013). Although our paper is only focused on the distributional aspects, we think that further research should pay attention to the relationship between social preferences (presumably in favour of shifting part of the tax burden towards the top income taxpayers) and the willingness of governments to implement them in their tax reform agendas. ${ }^{6}$

\footnotetext{
6 See Ballard-Rosa et al. (2017) on income tax policy preferences in the United States, and Profeta and Scabrosetti (2017) for European countries .
} 
Acknowledgements Onrubia and Rodado acknowledge the financial support from the Spanish Ministry of Economy and Competitiveness (Project ECO2016-76506-C4-3-R). Earlier versions of this paper were presented at the $5^{\text {th }}$ World Congress of the International Microsimulation Association (LISER, Esch-sur-Alzette, Luxembourg), the XXIII Spanish Meeting of Public Economics (Ourense, Spain), the XIX Spanish Meeting of Applied Economics (Sevilla, Spain), and seminars held at the University of Valencia and European Commission JRC-Seville. They gratefully acknowledge the useful comments and suggestions received from referees and editor, Julio López-Laborda and the participants in the abovementioned meetings. All errors remain the responsibility of the authors. The views expressed are purely those of the authors and may not in any circumstances be regarded as stating an official position of the European Commission.

\section{References}

Alvaredo, F. (2011). A note on the relationship between top income shares and the Gini coefficient. Economics Letters, 110: 274-277. https://www.gc.cuny.edu/CUNY_GC/media/CUNY-GraduateCenter/PDF/Centers/LIS/Milanovic/papers/1997/gini_branko.pdf

Atkinson, A. B., Piketty, T. and Saez, E. (2011). Top incomes in the long run of history. Journal of Economic Literature, 49: 3-71. https://eml.berkeley.edu/ saez/atkinson-piketty-saezJEL10.pdf

Ballard-Rosa, C., Martin, L., and Scheve, K. (2017). The structure of American income tax policy preferences. Journal of Politics, 79: 1-16. https://www.journals.uchicago.edu/doi/abs/10.1086/687324?journalCode=jop\&mobileUi=0\&

Diamond, P. and Saez, E. (2011). The case for a progressive tax: from basic research to policy recommendations. Journal of Economic Perspectives, 25: 165-190. http://piketty.pse.ens.fr/files/DiamondSaez2011.pdf

Förster, M., Llena-Nozal, A. and Nafilyan, V. (2014). Trends in top incomes and their taxation in OECD Countries. OECD Social, Employment and Migration Working Papers, 159, OECD Publishing. http://praha.vupsv.cz/fulltext/ul_1710.pdf

Gale, W. G., Kearny, M. S. and Orszag, P. R. (2015). Would a significant increase in the top income tax rate substantially alter income inequality? Economic Studies at Brookings, September 2015. https://www.brookings.edu/wp-content/uploads/2016/06/would-top-income-tax-alter-incomeinequality.pdf

Hettich, W., Profeta, P. and Winer, S. L. (2013). Political economy of taxation, in Oxford Bibliographies Articles: Political Science, Oxford University Press.

Kakwani, N. C. (1977). Measurement of tax progressivity: an international comparison. Economic Journal, 87: 71-80. https://www.jstor.org/stable/2231833?seq=2\#metadata_info_tab_contents 
Lambert, P. J. and Aronson, J. R. (1993). Inequality decomposition analysis and the Gini coefficient revisited. Economic Journal, 103: 1221-1227.

https://www.jstor.org/stable/2234247?seq=1\#metadata_info_tab_contents

Musgrave, R. A. and Thin, T. (1948). Income tax progression, 1929-48. Journal of Political Economy, 56: 498-514.

https://www.journals.uchicago.edu/doi/10.1086/256742

Pérez, C., Villanueva, J., Burgos, M. J., Pradell, E. and Moreno, A. (2014). La muestra de IRPF de 2011: Descripción general y principales magnitudes. Working Document, 17-2014, Instituto de Estudios Fiscales, Madrid.

Pfähler, W. (1984). Linear' income tax cuts: distributional effects, social preferences and revenue elasticities. Journal of Public Economics, 24: 381-388.

https://www.sciencedirect.com/science/article/abs/pii/0047272784900173

Piketty, T. (2014). Capital in the 21st Century. Harvard University Press, Cambridge, MA. https://www.hup.harvard.edu/catalog.php?isbn=9780674430006

Piketty, T., Saez, E. and Stantcheva, S. (2014). Optimal taxation of top labor incomes: a tale of three elasticities. American Economic Journal: Economic Policy, 6: 230-271. https://eml.berkeley.edu/ saez/piketty-saez-stantchevaAEJ14.pdf

Profeta, P. and Scabrosetti, S. (2017). The political economy of taxation in Europe. Hacienda Pública Española/Review of Public Economics, 220: 139-172. https://www.researchgate.net/publication/318344113_The_Political_Economy_of_Taxation_in_E urope

Reynolds, M. and Smolensky E. (1977). Public expenditures, taxes, and the distribution of income: The United States, 1950, 1961, 1970. Academic Press, New York.

https://www.elsevier.com/books/public-expenditures-taxes-and-the-distribution-ofincome/reynolds/978-0-12-586550-0

Rietveld, P. (1990). Multidimensional inequality comparisons: On aggravation and mitigation of inequalities. Economics Letters, 32: 187-192.

https://www.sciencedirect.com/science/article/pii/016517659090075C

Saez, E. and Zucman, G. (2019). “Alexandria Ocasio-Cortez's Tax Hike Idea Is Not About Soaking the Rich. It's about curtailing inequality and saving democracy”. The New York Times, January $22^{\text {th }}$, 2019.

https://www.nytimes.com/2019/01/22/opinion/ocasio-cortez-taxes.html 


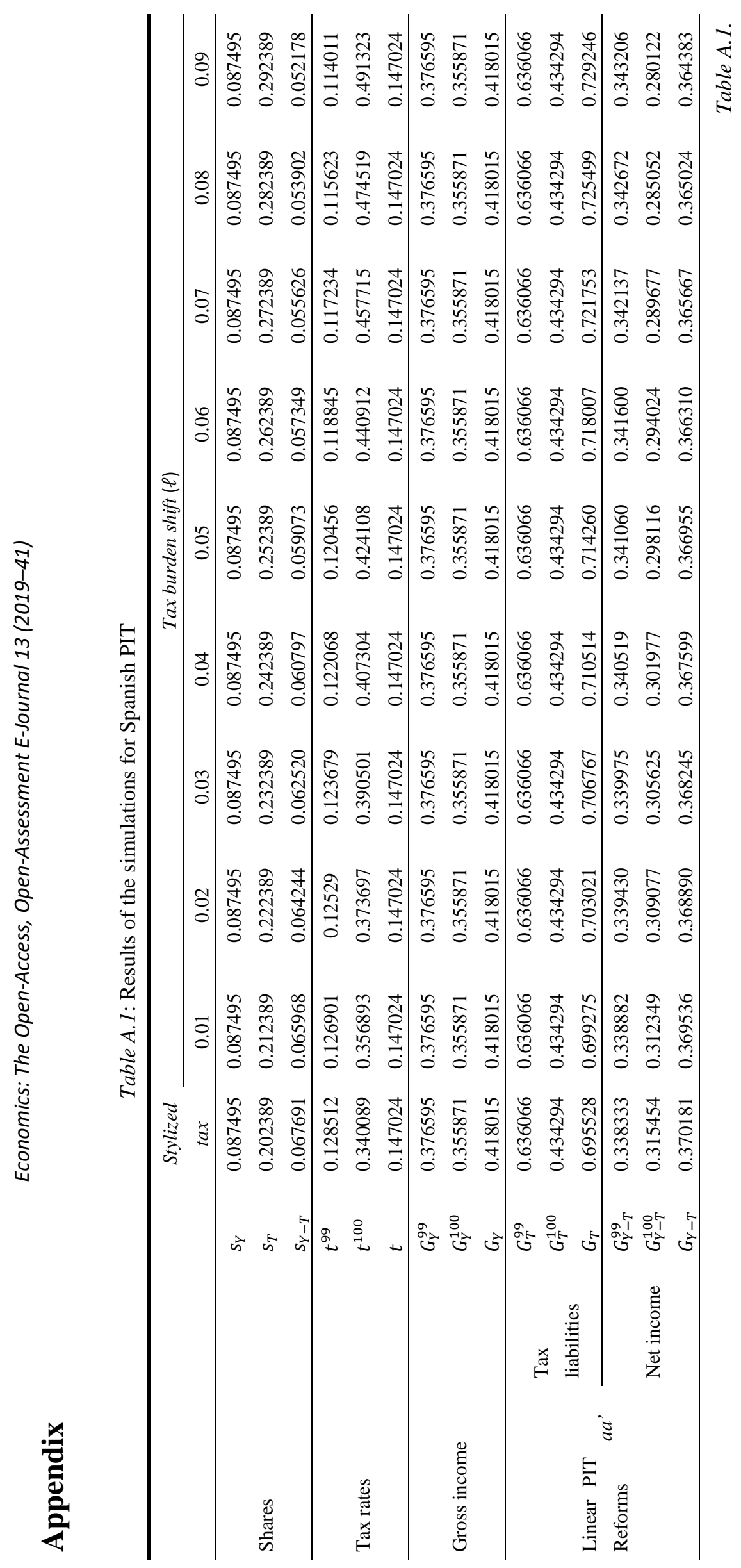




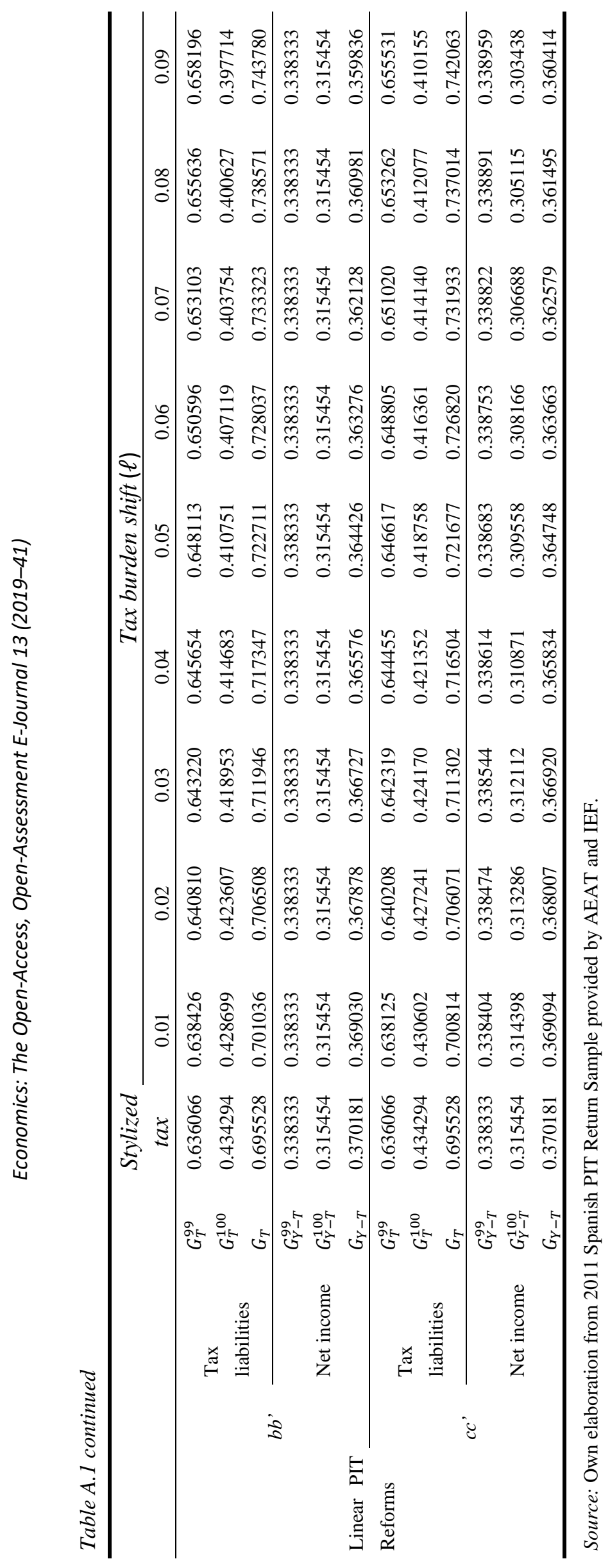




\section{Economics}

Please note:

You are most sincerely encouraged to participate in the open assessment of this article. You can do so by either recommending the article or by posting your comments.

Please go to:

http://dx.doi.org/10.5018/economics-ejournal.ja.2019-41

The Editor 